\title{
EL CAMBIO DE JURISPRUDENCIA POR LA CONTRALORÍA GENERAL DE LA REPÚBLICA: ¿CÓMO DETERMINAR SUS EFECTOS EN EL TIEMPO?
}

\author{
THE OVERRULING OF PRECEDENTS BY THE COMPTROLLER- \\ GENERAL: HOW TO ASCERTAIN ITS EFFECTS OVER TIME?
}

\author{
Jaime Phillips Letelier
}

\begin{abstract}
RESUMEN: La Contraloría General de la República, al introducir un cambio de criterio, no suele argumentar por qué concreta de una forma u otra los efectos en el tiempo de la nueva jurisprudencia. Lo anterior es problemático dado el efecto normativo que tiene la jurisprudencia de este organismo. Por esto, se proponen criterios que permitirán: resolver cómo concretar los efectos temporales de un cambio de jurisprudencia, limitar la aplicación extensiva de la retroactividad favorable y analizar cómo implementar un cambio de jurisprudencia motivado por la ilegalidad de un criterio anterior.
\end{abstract}

Palabras clave: Contraloría General, Jurisprudencia, Retroactividad, Temporalidad.

ABSTRACT: Beyond the arguments that justify a change in the administrative jurisprudence, the Comptroller-General does not usually give reasons to justify a specific over time implementation of a precedent shift. This paper proposes criteria that will allow the following: solving the problem of how to specify the temporal effects of a change of jurisprudence, limiting the extensive application of favourable retroactivity and to analyse how to implement a change of jurisprudence motivated by the illegality of a previous criterion.

Keywords: Comptroller-General, Precedents, Retroactivity, Temporality.

\section{INTRODUCCIÓN}

Entre las funciones de la Contraloría General de la República (CGR) está la de velar por la legalidad de los actos de los organismos administrativos ${ }^{1}$. Para cumplir esta función puede emitir informes y dictámenes, que son actos de naturaleza declarativa e interpretati$\mathrm{va}^{2}$. Estos actos se entienden incorporados a las leyes o reglamentos interpretados, de ma-

\footnotetext{
Doctor en Derecho. Profesor de Derecho Administrativo, Universidad Finis Terrae. Dirección postal: Avenida Pedro de Valdivia 1509, Providencia. Código Orcid: 0000-0002-4054-3187. Correo electrónico: jphillips@uft. cl. Agradezco los comentarios de Jaime Arancibia, Cristóbal Aguilera y Alonzo Ramírez a borradores previos de este trabajo; y también las incisivas sugerencias de los árbitros anónimos, que ayudaron mucho a mejorar este trabajo. Asimismo, le doy las gracias a Camilo Mirosevic por sus comentarios y por darme la posibilidad de hablar de estos temas con los funcionarios de la División Jurídica de la Contraloría General de la República, quienes me hicieron muy interesantes observaciones. Todos los posibles errores son de mi responsabilidad. Mi mayor gratitud es para mi hermana Melania, quien me recibió en su casa y acompañó durante la redacción de este trabajo.

${ }^{1}$ Artículo 98, Constitución Política de la República, Chile; artículo 8º inciso 1º, Ley No 10.336 de 1952.

2 VAldivia (2018) pp. 197-198.
} 
Phillips Letelier, Jaime " "El cambio de jurisprudencia por la Contraloría General de la República ..."

nera que no rige para ellos la prohibición de retroactividad ${ }^{3}$. En forma adicional, los precedentes de la CGR conforman el conjunto denominado "jurisprudencia administrativa", la cual debe ser observada por los órganos administrativos en la resolución de situaciones futuras semejantes ${ }^{4}$.

En un reciente estudio he analizado la forma en que opera esta obligatoriedad general de la jurisprudencia de la CGR consagrada en los artículos $6^{\circ}$ y 19 de la Ley $10.336^{5}$. Esta obligatoriedad no debe ser asimilada a la de las normas generales y abstractas, como las leyes, sino como una jurisprudencia referida a un conjunto de casos particulares que se aplica a otros semejantes; lo que tiene importantes consecuencias desde el punto de vista de la publicidad que deben recibir los precedentes que conforman la jurisprudencia administrativa y de cómo estos deben ser aplicados a casos futuros.

Este carácter obligatorio ha hecho proliferar estudios que analizan las distintas líneas jurisprudenciales adoptadas por la CGR en los más diversos temas ${ }^{6}$. Además, también se han elaborado estudios sobre el estándar de fundamentación que debe observar esta entidad para modificar su jurisprudencia ${ }^{7}$, lo que es necesario por razones de justicia, para evitar una excesiva rigidez del sistema o para hacer frente a un cambio de circunstancias ${ }^{8}$.

La mencionada flexibilidad presenta un problema que hasta ahora ha pasado desapercibido por la doctrina. Si la jurisprudencia de la CGR es una fuente formal del derecho, ¿puede un cambio de jurisprudencia ser aplicado con efecto retroactivo? Ya se señaló que la CGR entiende que sus informes o dictámenes, por ser de naturaleza interpretativa, se entienden incorporados a las normas interpretadas, de manera que pueden ser aplicados con efecto retroactivo. Pero no ocurre lo mismo cuando la CGR abandona la solución primigenia adoptada respecto de cierto asunto y la sustituye por otra. En tal caso, este organismo ha entendido que sus cambios de jurisprudencia no pueden tener efecto retroactivo?

Poca atención se ha prestado al problema de cómo determinar los efectos temporales de un cambio de jurisprudencia de la CGR. Aplicar esta regla de no-retroactividad pareciera ser algo simple: el nuevo precedente no puede cobrar efecto respecto de hechos regidos por el precedente anterior. Una prohibición de retroactividad puede ser aplicada de muchas maneras, dependiendo de los hechos sobre los cuales un cambio de criterio produce sus efectos.

\footnotetext{
3 Madariaga (1993) p. 181. En contra de esta idea, GuZmán (2020) pp. 118-119, aunque, como se verá, en la CGR ha primado la idea de que sus interpretaciones se entienden incorporadas a las normas interpretadas y se aplican con efecto retroactivo, salvo que se verifique un cambio de jurisprudencia.

4 Artículo 6o y 19, Ley No 10.336, de 1952. Ver también, GuZMán (2019) pp. 22-24.

5 Phillips (2020b).

6 Por ejemplo, ver Fuentes (2020) pp. 31-34; Ponce (2020) pp. 43-70; Boettiger (2013) pp. 309-326; MiLLAR (2012) pp. 417-430.

7 Cordero (2020b) pp. 130-133; Guzmán (2019), pp. 125-126; Bermúdez (2016) pp. 231-232. y Soto (1999) pp. 309-403.

8 Cross y Harris (2004) p. 104; Díez (2008) pp. 415-416. Ver también, Hart (2012) p. 130.

9 Por ejemplo, ver Dictámenes CGR números 74.506 (2021), 62.732 (2020), 25.714 (2019), 26.211 (2018), 40.086 (2015), entre otros. Más adelante, se analizarán en detalle muchos ejemplos sobre cómo se ha concretado la irretroactividad de los cambios de jurisprudencia de la CGR.
} 
La CGR no suele dar una fundamentación específica de por qué concreta los efectos temporales de un cambio de jurisprudencia de una determinada manera, habiendo varias posibles. En este contexto, la hipótesis de este trabajo es que la CGR tiene un deber de fundamentar por qué decide concretar los efectos en el tiempo de un cambio de jurisprudencia de una determinada forma, ya sea cuando determina el espacio temporal de vigencia de un criterio abandonado, cuando aplica la llamada "retroactividad favorable" o cuando abandona un criterio jurisprudencial por razones de legalidad ${ }^{10}$.

Para demostrar esta hipótesis se hará un análisis dogmático de las normas aplicables a la CGR y un análisis jurisprudencial. Para el análisis jurisprudencial se hizo una búsqueda a través de la voz "reconsidera" en la base jurisprudencial de la $\mathrm{CGR}^{11}$, y una búsqueda de jurisprudencia judicial de conflictos jurídicos en torno a la reconsideración de precedentes de la CGR. De allí, se hizo una selección cualitativa de las decisiones más representativas de las principales tendencias jurisprudenciales. Tratándose de un análisis dogmático y jurisprudencial, este trabajo no abordará el problema de los elementos (internos o exógenos) que inducen a los funcionarios a introducir un cambio de jurisprudencia, ya que se trata de un análisis de sociología legal que escapa al método que se utilizará.

El objetivo de este artículo es criticar cómo ha sido abordado hasta ahora por autoridades administrativas y judiciales el problema de los efectos temporales de un cambio de jurisprudencia de la CGR, para luego proponer criterios que sirvan de orientación al momento de determinar los efectos en el tiempo de un cambio de criterio. Todo esto se hará en tres partes:

1. En un primer apartado se mostrará cómo ha sido entendido el principio de irretroactividad aplicado a los cambios de jurisprudencia de la CGR. Este análisis demostrará que existen diversas líneas jurisprudenciales al interior de la CGR sobre cómo concretar los efectos temporales de un cambio de precedente, lo que, a su vez, lo anterior ha generado distintas respuestas por parte de los tribunales superiores de justicia.

2. En un segundo apartado, se harán tres críticas a cómo ha sido abordado el problema hasta ahora. Primero, la falta de justificación de por qué se concretan los efectos en el tiempo de un cambio jurisprudencial de una manera sin tener en cuenta otras posibles. Segundo, la cuestionable aplicación extensiva de la idea de retroactividad favorable realizada por la Corte Suprema. Tercero, el silencio de la CGR en torno al problema de la ilegalidad del precedente abandonado.

\footnotetext{
10 La literalidad de los artículos $6^{\circ}$ y 19 de la LEY 10.336 muestra que lo que tiene efecto normativo es la "jurisprudencia” de la CGR, la que está compuesta por una multitud de dictámenes, informes, decisiones; que son los "precedentes" de la CGR. De este modo, el objeto de este trabajo, en estricto rigor, es el problema de los efectos temporales de los cambios de jurisprudencia provocados por la inserción de un precedente que implica un cambio de criterio. Considerando lo anterior, en este trabajo usaré indistintamente las expresiones "cambio de jurisprudencia", "cambio de precedente", "abandono de precedentes", "cambio de criterio" y otras análogas, para referirme al acto por el cual la CGR introduce un precedente que implica una variación de su jurisprudencia.

11 La base de jurisprudencia de contraloría se encuentra disponible en: https:/www.contraloria.cl/web/cgr/ buscar-jurisprudencia2. Fecha de consulta: 16 de septiembre de 2021.
} 
3. En un tercer apartado, se propondrán soluciones que permitirán salvar las críticas formuladas. Primero, se señalará qué elementos es preciso tener en cuenta para determinar los efectos temporales de un cambio jurisprudencial y cómo fundamentar tal decisión. Segundo, se mostrará cómo limitar de modo razonable la retroactividad favorable. Tercero, se analizará cómo determinar cuándo un precedente abandonado es ilegal y en qué casos un cambio de jurisprudencia motivado por razones de legalidad no debe ser aplicado con efecto retroactivo.

\section{EL CAMBIO DE JURISPRUDENCIA Y SUS EFECTOS EN EL TIEMPO}

El problema de la retroactividad en nuestro ordenamiento jurídico ha sido estudiado en mayor medida a propósito de los efectos en el tiempo de la ley ${ }^{12}$. Lo anterior es interesante, porque el criterio consagrado en el artículo $9^{\circ}$ del Código Civil ("[1]a ley solo puede disponer para lo futuro, y no tendrá jamás efecto retroactivo") tiene múltiples concreciones en su normativa especial: la Ley sobre efecto retroactivo de las leyes (LER).

Por ejemplo, los artículos 21 y 22 de la LER permiten que un contrato o un acto de adjudicación produzcan sus efectos conforme con la regulación en que se perfeccionaron, aunque esta cambie en forma posterior. Por su parte, los artículos 13 y 16 establecen que el nacimiento de un derecho real se rige por la ley vigente en ese momento, pero en cuanto a sus cargas o extinción se rigen por la nueva ley. De esta manera, a diferencia del caso anterior, la antigua ley no acompaña al derecho real hasta su extinción (como sí ocurre con los contratos), sino que los derechos y cargas de este se pueden ver alterados por una ley sobreviniente. Algo similar ocurre con las normas sobre prescripción, donde se establece un derecho de opción en favor del prescribiente ${ }^{13}$.

Esta dispersión de criterios puede ser explicada porque, en definitiva, existen muchas formas de ver la conexión del pasado con el presente y la relación entre el acto interpretativo y las normas interpretadas ${ }^{14}$. En este sentido, en materia de interpretación administrativa, Guzmán Brito distingue entre el efecto ad preterita y el retroactivo ${ }^{15}$. El efecto ad preterita es el propio del acto interpretativo (por ejemplo, de una ley interpretativa) que despliega sus efectos antes de su propia vigencia, lo que tiene como límite la fecha de vigencia del acto interpretado; en cambio, retroactividad es el efecto de una norma o decisión con anterioridad a su fecha de vigencia.

Lo anterior es útil para entender los problemas de temporalidad del cambio de precedente de la CGR. Estos problemas siempre se producen en un contexto normativo (legal o reglamentario) estable; de manera que los efectos temporales de un cambio de jurisprudencia siempre tienen como límite la fecha de vigencia de las normas aplicadas en ese caso. Lo anterior no impide que existan muchas formas de concretar los efectos en el tiempo de un cambio de precedente dentro del límite señalado.

\footnotetext{
12 Claro (2013) p. 68; Alessandri, Somarriva y Vodanovic (2005) p. 233; Silva (1993) pp. 107-108; AylWin y AzÓCAr (1996) p. 50.

13 Artículo 25, Ley sobre efecto Retroactivo de las leyes (s/n) de 1861.

14 Schneider (2002) p. 261. Ver también, Barrero (2003) p. 141.

15 GuZMán (2019) pp. 117-119.
} 
Por esto, es útil asumir una nomenclatura que permita diferenciar las distintas formas de retroactividad existentes. Podemos llamar "retroactividad total" al efecto del cambio de jurisprudencia respecto de hechos concluidos con anterioridad a su vigencia. A su vez, podemos llamar "retroactividad parcial" al efecto de un cambio de jurisprudencia que, desde la fecha del cambio, alcanza el normal desenvolvimiento de los efectos de un acto o contrato perfeccionado durante la vigencia de una jurisprudencia anterior. Por último, podemos designar como "efecto prospectivo" a aquel que se refiere a hechos que se ejecuten o actos que se celebren con posterioridad a la vigencia de la nueva jurisprudencia. Estas distinciones tienen utilidad como marco comparativo para entender cómo la CGR ha determinado los efectos en el tiempo de sus cambios de precedente.

\section{EFECTO PROSPECTIVO}

Como punto de partida, se examinará un caso donde la CGR optó por dar solo efecto prospectivo a un cambio de jurisprudencia. Se trata del dictamen 92.308 de 2016, en el caso que denominaré Máquinas de Juego. Antes de este pronunciamiento, la CGR entendía que, para otorgar patentes municipales en negocios con máquinas de juego, cada municipio debía formarse convicción de que las máquinas eran de aquellas donde predominaba la destreza física y no el azar, para efectos de no infringir las normas pertinentes ${ }^{16}$.

Esta jurisprudencia no era satisfactoria, pues daba lugar a decisiones poco objetivas y a una dispersión de criterios. Por esto, la CGR resolvió que, para otorgar estas patentes, se debía tener presente la lista de juegos de azar de la Superintendencia de Casinos y, en caso de dudas, se debía solicitar un informe a este organismo. Con todo, esto no afectó a las patentes ya otorgadas conforme con la antigua jurisprudencia ${ }^{17}$.

La decisión fue impugnada por una asociación gremial, pues implicaba mayores exigencias para el otorgamiento de estas patentes; lo que dio lugar a la causa FIDEN A.G. con Contralor General de la República. La Corte Suprema asumió una posición de deferencia hacia lo resuelto por la CGR, al considerar que el cambio de criterio respondía a una necesidad pública manifiesta ${ }^{18}$.

Ahora bien, los tribunales no han siempre sido deferentes con los criterios de la CGR en este tipo de casos. Existen situaciones en que la Corte Suprema ha cuestionado lo decidido por la CGR y ha resuelto darle efecto retroactivo a un cambio de precedente por ser el anterior contrario a derecho.

Lo anterior se puede observar en Óscar Ulloa y otros con Gendarmería de Chile, caso que denominaré Descuentos en Gendarmería. Antes de la emisión del dictamen 57.424 de 2009, la CGR consideraba que los descuentos en las remuneraciones de funcionarios de Gendarmería de Chile originados en compromisos financieros con terceros amparados por el artículo 164 de la Ley 14.171 eran de carácter legal y, por tanto, no tenían límite ${ }^{19}$. Des-

\footnotetext{
16 Artículos 1466 y 2259, Código Civil, Chile; Ley No 19.995 de 2005.

17 Dictamen CGR No 92.308 (2016).

18 FIDEN A.G. CON CONTRALOR GENERAL DE LA REPÚbLICA (2018), considerando $13^{\mathrm{a}}$.

19 Esta norma permite deducir de los sueldos de estos funcionarios públicos determinadas sumas por concepto de préstamos, fianzas seguros y otros servicios; de modo que la discusión recaía en si estos descuentos eran le-
} 
pués, haciendo un reestudio del asunto, la CGR concluyó que en realidad tales descuentos sí tenían como límite el $15 \%$ de la remuneración del funcionario respectivo ${ }^{20}$. Sin embargo, luego se declaró que tal determinación no afectaba los contratos celebrados con anteriori$\mathrm{dad}^{21}$. De este modo, el nuevo criterio tuvo solo efecto prospectivo, pues solo debía alcanzar a aquellos actos celebrados con posterioridad a su vigencia.

Aunque se haya decidido que el nuevo criterio no alcanzaba a los contratos anteriores, dándole solo efecto prospectivo, sin decirlo expresamente, la nueva interpretación de la CGR insinúa que el criterio anterior era ilegal. Por esto, los funcionarios recurrieron de protección insistiendo en que los descuentos que excedían el 15\% de su remuneración eran ilegales y tales contratos debían estimarse como contrarios a derecho a pesar de haber sido celebrados durante la vigencia del precedente que no contemplaba límites para ese tipo de descuentos. La Corte Suprema declaró la ilegalidad de tales descuentos y los hizo cesar ${ }^{22}$. De este modo, podemos decir que el tribunal optó por ampliar el efecto del nuevo criterio por considerar que el anterior era ilegal ${ }^{23}$.

\section{EFECTO RETROACTIVO PARCiAL}

Hay pronunciamientos de la CGR que permiten darle a un cambio de precedente efecto retroactivo parcial. De esta manera, el nuevo criterio alcanza a actos administrativos emitidos en forma anterior al cambio jurisprudencial. Para esto se puede considerar el caso del dictamen 50.185 de 2007, caso que llamaré Incompatibilidad de Remuneraciones. La solicitante se desempeñaba como directora suplente del Servicio de Salud de Atacama desde el 1 de abril de 2006. A esa fecha, también desempeñaba el cargo de concejal, teniendo derecho a percibir una remuneración por ambos cargos de acuerdo con el dictamen 19.598 de 2004. El 22 de septiembre de 2006 hubo un cambio de jurisprudencia con la emisión del dictamen 44.902 de 2006, donde se indicó que ambas remuneraciones eran incompatibles.

El cambio de jurisprudencia aparece motivado por una reinterpretación de las leyes aplicables. Al respecto, hay que considerar que el artículo 66 de la Ley 19.882 hace aplicables como excepciones a la obligación de dedicación exclusiva en un cargo de alta dirección pública las mencionadas en el artículo $1^{\circ}$ de la Ley 19.863. Una de estas excepciones consiste en ser integrante de "consejos de empresas o entidades del Estado"24.

Durante la vigencia del dictamen 19.598 de 2004, se entendía que el cargo de concejal municipal se encontraba dentro de la excepción, por lo que su remuneración y cargo eran compatibles con un cargo de alta dirección pública de dedicación exclusiva. Pero el dictamen 44.902 de 2006 rechazó tal interpretación, señalando que, "atendidas las defini-

gales por ser autorizados por el artículo 164 de la Ley 14.171 o si eran convencionales por ser originados en los actos jurídicos mencionados en la norma.

20 Dictamen CGR No 57.424 (2009).

21 DiCTAMEN CGR No 27.314 (2010).

22 Óscar Ulloa y otros con Gendarmería de Chile (2012), considerando 6º. Ver también, Mamani CON MUNICIPALIDAD DE PUTRE Y OTRO (2019) considerandos $5^{\circ}$ y $6^{\circ}$.

23 Otros casos donde se produce esta discusión: CMPC MADERAS S.A. CON SERVICIO AGRÍCOLA Y GANADERO (2013) y ABUFRUT LIMITADA CON SERVICIO AGRÍCOLA Y GANADERO (2015).

24 Artículo $1^{\circ}$, inciso 5, LEY 19.863 de 2003. 
ciones dadas por el Diccionario de la Real Academia Española, la denominación de 'concejo', del latín concilium, dice relación específica con el ayuntamiento, esto es, el municipio; por el contrario, el 'consejo' es cualquier órgano colegiado de la administración al que se le atribuyen funciones" 25 . De este modo, la palabra "concejo" (utilizando la letra "c" en la segunda sílaba) estaría referida al municipio o ayuntamiento, mientras que la palabra "consejo" (utilizando la letra "s" en la segunda sílaba) significa "cualquier órgano colegiado".

La afectada solicitó la reconsideración de dicho dictamen, señalando, inter alia, que se le estaba dando efecto retroactivo, porque afectaba su posición jurídica adquirida con anterioridad. Frente a ello, la CGR resolvió que, conforme con la jurisprudencia anterior al 22 de septiembre de 2006, la solicitante percibió de manera válida ambas remuneraciones, pero que después de esa fecha solo tiene derecho a percibir la remuneración que le corresponde como directora del Servicio de Salud de Atacama ${ }^{26}$.

De este modo, se entiende que la funcionaria percibió ambas remuneraciones de modo válido antes del cambio de jurisprudencia, de manera que se excluye el efecto retroactivo total. Pero se permite el efecto retroactivo parcial, porque la nueva jurisprudencia proyectó sus efectos de modo inmediato sobre actos administrativos perfeccionados en el pasado.

\section{EFECTO RETROACTIVO TOTAL}

Existe un grupo de casos en que la jurisprudencia de la CGR ha admitido darle efecto retroactivo total a un cambio de criterio. Se trata de situaciones en que alguien, desfavorecido por un determinado precedente de la CGR, provoca por medio de una solicitud un cambio en la jurisprudencia. Los hechos sobre los cuales recae el pronunciamiento, lógicamente, ocurrieron durante la vigencia del precedente abandonado. Con todo, la CGR decide darle efecto retroactivo al nuevo criterio para beneficiar a quien lo gatilló.

Un ejemplo bastará para explicar lo anterior. En el caso que llamaré Pensiones de Desahucio, por medio del dictamen 94.432 de 2014, se modificó la forma de calcular las pensiones de desahucio de los miembros de las Fuerzas Armadas, dando un resultado más beneficioso para los militares retirados que el existente antes de la emisión de ese acto. Para determinar los efectos en el tiempo del dictamen más beneficioso, se emitió el dictamen 40.086 de 2015. En este se resolvió que el nuevo criterio se aplicaría a todos los militares retirados a partir de la emisión del dictamen 94.432 de 2014, esto es, aquellos en que el hecho jurídico pertinente (el retiro) se produzca durante la vigencia del nuevo criterio, y a todos aquellos que, a pesar de haberse retirado durante el criterio antiguo, solicitaron la modificación de la pensión de desahucio antes de la emisión del dictamen 94.432 y su solicitud se encontraba pendiente a la fecha de emisión del criterio más beneficioso ${ }^{27}$.

En la situación anterior, en la práctica, se le da efecto retroactivo a un cambio de jurisprudencia, pues se aplica a hechos regidos por el precedente anterior. En efecto, la pensión del personal de las Fuerzas Armadas se determina según el precedente vigente al

25 Dictamen CGR No 44.902 (2006).

26 Dictamen CGR No 50.185 (2007).

27 Dictamen CGR No 40.086 (2015). 
Phillips Letelier, Jaime "El cambio de jurisprudencia por la Contraloría General de la República ..."

momento de verificarse el retiro ${ }^{28}$, ya que la jurisprudencia de CGR "forma parte de las disposiciones" que rigen el retiro ${ }^{29}$. La excepción a la irretroactividad en este caso puede verse como necesaria para beneficiar con la aplicación del nuevo criterio a quien provocó dicho pronunciamiento y, por extensión, a quienes tenían solicitudes pendientes en el mismo sentido. Esta excepción a la irretroactividad configuraría un caso de retroactividad total.

La forma recién mencionada de concretar los efectos en el tiempo de un cambio de precedente ha sido validada por la Corte Suprema en situaciones similares ${ }^{30}$. Sin embargo, ello no ha sido siempre así. El mencionado tribunal ha considerado que la CGR está en obligación de darle efecto retroactivo a un cambio de criterio si tiene un efecto favorable hacia el solicitante. Lo anterior puede ser observado en la causa Sepúlveda y Cárcamo con Contraloría Regional de los Ríos ${ }^{31}$, referido al dictamen 20.921 de 2018, en el caso que llamaré Fuero Maternal.

Hasta antes de ese pronunciamiento se consideraba que las funcionarias contratadas en calidad de reemplazo no recibían la protección del fuero maternal contemplada en el artículo 201 del Código del Trabajo. Frente a esto, dos funcionarias alegaron haber sido desvinculadas con infracción a lo dispuesto en ese dictamen. Con todo, la Contraloría Regional de los Ríos resolvió que no era posible aplicar el dictamen 20.921 de 2018 al caso de ellas, pues su situación acaeció durante la vigencia del precedente anterior: el dictamen 19.511 del año 2009.

Conociendo de un recurso de protección, la Corte Suprema resolvió que en este caso era necesario considerar la aplicación del artículo 52 de la Ley 19.880. Esta norma, si bien en principio prohíbe la retroactividad del acto administrativo, permite darle efecto retroactivo a una decisión cuando tiene efecto favorable para el interesado. Por lo tanto, en casos como estos, la autoridad tiene que considerar si el nuevo dictamen favorece o no a los interesados y, sobre la base de ello, decidir si darle efecto retroactivo o no; lo que en este caso la autoridad debió hacer porque de lo contrario "se afectaría gravemente la igualdad ante la ley y el principio de buena fe administrativa" ${ }^{2}$. Con esto, en la práctica se obligó a la CGR a darle efecto retroactivo a su nueva jurisprudencia.

Finalmente, se puede observar un caso de retroactividad total en el dictamen 24.731 de 2019. En virtud de este pronunciamiento la CGR modificó su jurisprudencia relativa al plazo de prescripción aplicable al derecho administrativo sancionador (caso Prescripción de Sanciones Administrativas). El antiguo precedente establecía que tal plazo era de seis meses, aplicando en forma analógica el artículo 96 del Código Penal. Esa interpretación

28 DiCTAMEN CGR No 14.292 (2007), que modificó la jurisprudencia asentada por los DiCTÁMENES CGR No 51.963 (2005) y 22.437 (2006) respecto de los efectos en el tiempo que tuvo la jurisprudencia iniciada por el Dictamen CGR No 37.859 (2000). Siguieron este criterio los DiCtámenes CGR No 60.094 (2008) y 48.688 (2009).

29 Dictamen CGR No 18.219 (2016). En el mismo sentido, ver también los DiCtámenes CGR No 68.704 (2016), 68.075 (2016), 53.891 (2016) y 46.046 (2016), todos en relación con el DICTAMEN CGR No 22.766 (2016).

30 Farmacología en Aquacultura Veterinaria FAV S.A. con INAPI (2020); Neftali Aguayo con Carabineros DE CHILE (2013).

31 Sepúlveda y Carcamo con Contraloría Regional de los Ríos (2020).

32 Mamani con Municipalidad de Putre Y OtRo (2019) considerando 17o. 
fue abandonada por otra que consideraba que, a falta de norma expresa referida al derecho administrativo, la prescripción debe ser aquella de cinco años regulada en el artículo 2515 del Código Civil ${ }^{33}$.

Al final del pronunciamiento se establece cómo se desplegarán los efectos en el tiempo del nuevo criterio. Se señala: "en resguardo del principio de seguridad jurídica, este nuevo criterio solo generará efectos para el futuro, sin alcanzar a las infracciones que ya prescribieron conforme al criterio sustituido". En consecuencia, solo aquellas infracciones en que el plazo de seis meses se hubiese completado antes de este pronunciamiento no se ven alcanzadas por el nuevo criterio. Sin embargo, las infracciones cometidas antes del cambio de jurisprudencia cuyo plazo de prescripción no se hubiese completado se rigen por el nuevo criterio. Esto es una hipótesis de retroactividad total, pues se aplica la nueva jurisprudencia a infracciones cometidas con anterioridad a su vigencia.

\section{IRRETROACTIVIDAD DEL CAMBIO DE JURISPRUDENCIA: PROBLEMAS Y OBJECIONES}

La jurisprudencia administrativa y judicial analizada en el apartado anterior permite observar lo complejo que puede ser la aplicación en el tiempo de un cambio de precedente de la CGR. En este apartado, se argumentará que existen tres deficiencias en cómo se ha abordado este problema hasta ahora: primero, la falta de fundamentación sobre por qué se concretan de una determinada manera los efectos en el tiempo del nuevo criterio; segundo, la aplicación extensiva de la retroactividad favorable, y, tercero, se criticará el silencio de la CGR en torno a la legalidad o ilegalidad del precedente que se abandona.

\section{EFECTOS EN EL TIEMPO: NECESIDAD DE FUNDAMENTACIÓN}

La doctrina en general habla de que un cambio de jurisprudencia debe estar justificado $^{34}$. Con esto, al cambiar de criterio, la CGR suele centrar sus esfuerzos en justificar por qué se debe abandonar el criterio antiguo por el nuevo. Pero al implantar el nuevo criterio, no se suele incluir una justificación de por qué se determinaron los efectos en el tiempo del cambio de una determinada manera.

A modo ejemplar, se pueden analizar dos pronunciamientos de la CGR. El primero de ellos es el dictamen 24.731 de 2019, del caso Prescripción de Sanciones Administrativas. Tal pronunciamiento discurre largamente sobre por qué se debiese abandonar la interpretación que hacía aplicable el artículo 96 del Código Penal (que regula un plazo de 6 meses para la prescripción de las faltas penales) y, en su lugar, aplicar el plazo de 5 años establecido en el artículo 2515 del Código Civil. Sin embargo, al referirse a los efectos en el tiempo

\footnotetext{
33 Aunque es claro que el cambio implementado por la CGR en esta materia está influido por un cambio jurisprudencial de la Corte Suprema (al respecto, ver LABORATORIOS LAFI LTDA. CON INSTITUTO DE SALUD PÚBLICA (2018), considerando $28^{\circ}$ y Cordero (2020a) pp. 369-370), tal como se dijo en la introducción, este trabajo no tiene por objeto indagar en los argumentos o motivaciones que determinan un cambio de precedente, sino la forma de concretar los efectos en el tiempo de una nueva jurisprudencia de la CGR cuando se verifica dicho cambio.

34 Cordero (2020b) pp. 134-135; Bermúdez (2016) pp. 231-232; Soto (1999) pp. 402-403.
} 
Phillips Letelier, Jaime "El cambio de jurisprudencia por la Contraloría General de la República ..."

de la nueva jurisprudencia se limita a señalar que regirá solo para el futuro, "sin alcanzar a las infracciones que ya prescribieron”.

Con esto, una infracción cometida antes del cambio, respecto de la cual no hubiese transcurrido el plazo de seis meses, se debiese regir por el criterio nuevo. Esto también es problemático pues pareciera que el plazo de cinco años comenzaría a correr antes de su vigencia. De este modo, es cuestionable que el cambio de criterio "genere efectos solo para el futuro", en circunstancias de que se refiere no solo a las infracciones que eventualmente se cometerían en el futuro, sino también a aquellas cometidas en el pasado cuyo plazo de prescripción no se hubiese completado a la fecha de cambio de jurisprudencia.

En lugar de ello, se podría haber adoptado otra regla para determinar los efectos en el tiempo: que las infracciones cometidas bajo el antiguo criterio se rigen por este y las cometidas en forma posterior se rigen por el nuevo. Esto, por lo demás, es el criterio que ha utilizado la Corte Suprema (en antiguos fallos de inaplicabilidad) al determinar los efectos en el tiempo de leyes que establecen sanciones administrativas ${ }^{35}$. Sin embargo, la CGR guarda silencio sobre por qué eligió esa determinada forma de concretar los efectos en el tiempo de una nueva jurisprudencia.

Además de lo anterior, la actual práctica de la CGR permite introducir discriminaciones arbitrarias y afectar el ejercicio de otros derechos. Lo anterior puede verse en la causa Farmacología en Aquacultura FAV S.A. con INAPI, referida al cambio de criterio introducido por el dictamen 16.587 de 2019 y al dictamen 25.534 de 2019, que concretó los efectos en el tiempo del primero. A este caso lo denominaré Patente de Invención.

Básicamente, el dictamen 16.587 de 2019 introdujo una interpretación más beneficiosa para los solicitantes de patentes de invención. Esto porque, en ese pronunciamiento, se entendió que el pago de los derechos establecidos en el artículo 18 bis E de la Ley 19.039 constituía una exigencia de tramitación y, en caso de incumplirse ese plazo, la solicitud podía ser desarchivada dentro de los 120 días siguientes sin perder la preferencia. Temporalmente, el nuevo criterio se comenzó a aplicar a las solicitudes archivadas a partir de su vigencia y retroactivamente a aquellas solicitudes que, aunque fueron archivadas durante la vigencia de la jurisprudencia más restrictiva, fueron formuladas por quienes provocaron el cambio de criterio introducido en el dictamen $16.587 \mathrm{y}$, por tanto, no a la empresa recurrente ${ }^{36}$.

Este criterio tiene problemas que pueden destacarse. La excepción a la irretroactividad consistente en extender la aplicación del nuevo criterio a quien lo provoca y a las solicitudes pendientes similares hace que la frontera de aplicación temporal de un criterio u otro no sea la distinción entre lo pasado y lo presente, sino el momento en que fue ingresada la respectiva solicitud. De este modo, una situación particular, regida por un determinado precedente, termina siendo resuelta en virtud de uno distinto porque con ocasión de ese caso la autoridad decidió modificar su jurisprudencia.

Resulta de esto que terminan existiendo dos situaciones idénticas, regidas por la misma legislación y cuyos hechos se verificaron durante la vigencia del mismo precedente; pero que son resueltas con criterios distintos porque las respectivas solicitudes fueron ingresadas

\footnotetext{
35 Alessandri (1965) considerando 2o; BANCO CRÉDITO E INVERSIONES (1966) considerando 5º.

36 Farmacología en Aquacultura Veterinaria FaV S.A. con INAPI (2020).
} 
en momentos distintos. Con esto, la sola consideración del momento en que fue ingresada una solicitud da lugar a una solución diferenciada para casos similares. Tal forma de concretar los efectos en el tiempo de un cambio de jurisprudencia puede tener resultados azarosos y es arbitraria, pues no existe ninguna explicación de por qué se cambia de criterio en un caso y no en otro. Por ejemplo, frente a diez solicitudes similares, la CGR podría resolver nueve de ellas bajo un criterio y cambiar su jurisprudencia en la décima declarando que esa fue la que provocó el cambio, la que regirá solo para el futuro.

Lo anterior, encierra una discriminación arbitraria prohibida por el artículo 19 No 2 de la Constitución ${ }^{37}$. Por esto, pienso que es necesario introducir dos mejoras para la mejor gestión de este asunto. Primero, la CGR debiese referirse de explícito al problema de los efectos temporales cuando decide reconsiderar su jurisprudencia anterior y justificar la decisión tomada. Segundo, se debiese abandonar el criterio de aplicar con efecto retroactivo la nueva jurisprudencia a quien provoca el cambio y buscar una regla distinta que conlleve un menor riesgo de arbitrariedad.

\section{LUCES Y SOMBRAS DE LA RETROACTIVIDAD FAVORABLE}

Para solucionar algunas de las complicaciones surgidas hasta ahora, la Corte Suprema ha ordenado considerar aplicar la excepción de retroactividad del artículo 52 de la Ley 19.880. Esto, por ejemplo, podría ser una solución aceptable para evitar introducir discriminaciones basadas en el momento en que se ingresó una solicitud.

Esto puede mostrarse con claridad si volvemos sobre el caso Fuero Maternal. En este caso, comentado más arriba, dos funcionarias impugnaron la decisión de una Contraloría Regional en virtud de la cual se negó a hacerles aplicable el derecho a fuero maternal que les reconoció el dictamen 20.921 de 2019. Esto porque su designación como reemplazantes había expirado con anterioridad a la fecha del cambio jurisprudencial introducido por el recién citado dictamen. A pesar de ello, la Corte Suprema resolvió en favor de las recurrentes señalando que la autoridad debió considerar aplicar la excepción de retroactividad favorable del artículo 52 de la Ley $19.880^{38}$.

Con esta sentencia, no se benefició solamente a quienes provocaron el cambio sino también a quienes se encontraban en una situación similar poco antes del cambio. Así, aplicar el artículo 52 de la Ley 19.880 permite soslayar tener que definir la frontera de aplicación en el tiempo del criterio nuevo sobre la base del momento en que se formuló una solicitud.

Sin embargo, es necesario proceder con cautela al dar efecto retroactivo favorable a un cambio de jurisprudencia. El artículo 52 de la Ley 19.880 señala: "[l]os actos administrativos no tendrán efecto retroactivo, salvo cuando produzcan consecuencias favorables para los interesados y no lesionen derechos de terceros". La norma contiene una prohibición de la retroactividad desfavorable y una habilitación para la retroactividad favorable, pero plantea algunas dudas: ¿se trata de una potestad reglada?, ¿los cambios favorables de

37 En este sentido, ver el voto de minoría del ministro Muñoz en NEFTALI AGUAYO CON CARABINEROS DE CHILE (2013).

38 Sepúlveda y CARCamo con Contralorí Regional de los Ríos (2020) considerando $15^{\circ}$. 
jurisprudencia siempre deben ser aplicados con efecto retroactivo? Responder afirmativamente es problemático, pues dar efecto retroactivo sin límites a todo cambio favorable impactaría en muchas decisiones pasadas y sería catastrófico para las finanzas públicas.

Lo anterior es patente en el caso del dictamen 22.766 de 2016 que introdujo el principio de confianza legítima en la no renovación de contratas administrativas (caso Contratas Administrativas). Tal principio fue utilizado en ese caso para resolver que la decisión de no renovar una contrata debe ser tomada mediante un acto positivo y fundado, respecto de aquellos funcionarios que hayan sido renovados dos o más veces. La jurisprudencia inaugurada con ese pronunciamiento fue aplicada en ese caso y en aquellos pendientes de resolución. Pero respecto de las no renovaciones ocurridas con anterioridad, respecto de las cuales no existía solicitud alguna a la fecha del dictamen 22.766 de 2016, la jurisprudencia aplicada fue la antigua, es decir, que la contrata expira ipso iure sin necesidad de fundamentación por la simple no renovación ${ }^{39}$.

El nuevo criterio se aplicó a quienes provocaron el cambio y a las solicitudes pendientes semejantes. Y aunque esta regla es discriminatoria, tiene una virtud: introduce un límite claro al efecto retroactivo de un cambio de jurisprudencia y así evita tener que revisar decisiones pasadas de un modo extensivo. De lo contrario, ¿qué impediría que un funcionario a contrata, no renovado el año 2009 o 2010 por una simple omisión, solicitase la aplicación del nuevo criterio a su caso particular? Pues nada. Por esto, al buscar una solución al problema de los efectos temporales de un cambio de jurisprudencia favorable, es necesario también encontrar un criterio que no sé lugar a una retroactividad favorable sin límites que sea imposible implementar sin generar graves consecuencias para la buena gestión al interior de la Administración Pública.

\section{UNA VERDAD INCÓMODA: LA ILEGALIDAD DEL PRECEDENTE}

Al modificar su jurisprudencia, muchas veces pareciera que la CGR lo hace por considerar que el antiguo criterio era contrario a derecho. Sin embargo, esta entidad suele guardar silencio sobre el problema de la legalidad o ilegalidad de la jurisprudencia abandonada. De este modo, al ser abandonada una jurisprudencia por razones de legalidad, ¿no se debiese implementar la nueva con efecto retroactivo? Tal es el efecto normal de la infracción al principio de legalidad ${ }^{40}$.

El problema es que la CGR no siempre se hace cargo de las consecuencias temporales que tiene el abandono de un precedente cuando esto se hace por razones de legalidad. Para ilustrar lo anterior, se puede mencionar la causa Abufrut Limitada con SAG, que podemos denominar como Tarifas por Inspecciones. En 1990 la CGR tomó razón de un decreto supremo del Ministerio de Agricultura que fijaba determinadas tarifas que el SAG podía cobrar. Años después, por medio del dictamen 18.390 de 2007, la CGR declaró que el SAG no podía cobrar tarifas a los particulares por aquellas inspecciones que debía realizar

\footnotetext{
39 Ver, por ejemplo, dictamen CGR No 68.704 (2016), Dictamen CGR 68.075 (2016), Dictamen CGR 53.891 (2016) y DiCTAMEN CGR 46.046 (2016).

40 Valdivia (2018) pp. 406-407.
} 
de oficio. De este modo, declaró abandonado el criterio según el cual el SAG podía cobrar tarifas por las inspecciones que debía realizar de oficio.

Lo anterior podría ser mirado como una declaración de ilegalidad también de todos aquellos cobros practicados entre 1990 y 2007. Por esto, una empresa demandó su restitución. Con todo, la Corte Suprema entendió que el cambio de precedente de la CGR solo podía tener efecto hacia el futuro y, en consecuencia, solo desde la emisión del dictamen el SAG debía abstenerse de cobrar por las inspecciones que debe hacer de oficio ${ }^{41}$. En contra de lo anterior, la Corte de Apelaciones de Santiago acogió una demanda de cobro de pesos en un caso idéntico, ya que entendió que el cambio de criterio implicaba una declaración de ilegalidad de la jurisprudencia abandonada ${ }^{42}$.

En estos casos, es claro que la discusión está en cómo se debiesen proyectar en el tiempo los efectos del nuevo precedente. Si se considera que el cambio de criterio lo es desde uno conforme a derecho a otro también conforme a derecho, el nuevo criterio solo debiese tener efecto prospectivo. Pero si se entiende que el precedente abandonado es contrario a derecho, el cambio de criterio debiese equivaler a una declaración de ilegalidad y, por tanto, el tribunal debiese reconocer las consecuencias patrimoniales que ello tiene.

Por esta segunda alternativa optó la Corte Suprema en el caso Descuentos en Gendarmería, al considerar ilegal el precedente de la CGR sobre descuentos en las remuneraciones de estos funcionarios. Podría argumentarse que esta solución es problemática, pues podría implicar corregir hacia el pasado muchos actos realizados al amparo del precedente declarado ilegal. En esta dirección apunta el voto de minoría de la Corte Suprema en este último caso, en el cual se avala el criterio de la CGR de no impedir que los acuerdos celebrados al amparo del antiguo precedente dejen de producir efectos sobre la base de la confianza legítima ${ }^{43}$.

Considerando lo anterior, una adecuada solución a este problema debiese pasar por abordarlo de modo más explícito. Guardar silencio sobre la legalidad o ilegalidad de la jurisprudencia abandonada es una postura ambigua que genera confusión. Sin embargo, también es importante limitar los efectos retroactivos de una declaración de ilegalidad, para no generar un excesivo desorden administrativo y proteger situaciones jurídicas consolidadas.

\section{PROPUESTAS PARA LOS PROBLEMAS DE TEMPORALIDAD DE LOS CAMBIOS DE JURISPRUDENCIA DE LA CGR}

Las objeciones planteadas en el apartado anterior dejan al descubierto tres problemas importantes. El primero es que, aunque existen muchas formas de concretar los efectos temporales de un cambio de jurisprudencia administrativa, la CGR no suele fundamentar su decisión de optar por una u otra forma. El segundo consiste en que la norma de retroactividad favorable del artículo 52 puede ser aplicada a los cambios de jurisprudencia de la

41 ABUfRUT LIMITADA CON SERVICIO AGRÍCOLA Y GANADERO (2015) considerandos $16^{\circ}$ y $17^{\circ}$.

42 CMPC MAdERAS S.A. CON SERVICIO AGRICOLA Y GANADERO (2013) considerando 4o. El recurso de casación interpuesto contra esta sentencia fue rechazado por la Corte Suprema por razones formales.

43 Óscar Ulloa y otros con Gendarmería de Chile (2012) considerando 4o del voto de minoría. 
CGR, pero no queda claro cuál debiese ser el límite de dicha retroactividad. El tercero es que la CGR no suele abordar de modo explícito el problema de ilegalidad del antiguo precedente cuando este es abandonado; lo que deja sin respuesta la pregunta de si el carácter de ilegal de la jurisprudencia abandonada debiese tener algún impacto en cómo se deben determinar los efectos en el tiempo del nuevo criterio. A continuación, se propondrán criterios para solucionar estos problemas.

\section{FUNDAMENTACIÓN Y TEMPORALIDAD}

La Ley 19.880 consagra un deber de fundamentar todo acto administrativo terminal ${ }^{44}$. El contenido específico de tal deber depende de la decisión que se está tomando. Así hay tantas fundamentaciones como decisiones una autoridad puede tomar. Esto es importante, pues si el concepto de retroactividad aplicado a los cambios de jurisprudencia de la CGR se encuentra en parte indeterminado $-\mathrm{y}$ dado que los conceptos jurídicos indeterminados admiten múltiples concreciones ${ }^{45}$ - , se puede concluir que los efectos temporales de un cambio de jurisprudencia deben ser concretados mediante una decisión fundada.

De este modo, teniendo en cuenta los problemas de temporalidad analizados, es posible afirmar que las razones que justifican un cambio de jurisprudencia no necesariamente son las que justifican una determinada concreción de los efectos en el tiempo de un nuevo criterio. Es posible desintegrar el deber de fundamentar la necesidad de introducir un cambio de criterio de la forma en que se desplegarán los efectos de ese cambio. Para entender lo anterior, es preciso distinguir entre tres elementos importantes: la idoneidad de un nuevo criterio, la justificación del efecto retroactivo y la justificación del efecto inmediato ${ }^{46}$.

Primero, la idoneidad está constituida por las características que tiene un nuevo criterio que justifican realizar un cambio de jurisprudencia. Puede ser de dos tipos: una idoneidad de necesidad, por la cual la se abandona una determinada jurisprudencia para sustituirla por otra por razones de mérito, oportunidad o conveniencia, y una idoneidad legal, por la cual la nueva jurisprudencia se introduce para corregir la ilegalidad del precedente que se abandona. Con esta distinción, se busca reflejar que abandonar un determinado precedente no siempre equivale a declarar la ilegalidad del anterior.

Segundo, aunque un nuevo criterio resulte ser más idóneo que los anteriores y, por tanto, haya buenas razones para implementar un cambio de jurisprudencia, no por ello se le puede dar efecto retroactivo total o parcial. Legislar con efecto retroactivo es considerado un anatema en todos los sistemas jurídicos, pero que decisiones con carácter declarativo tengan efecto retroactivo es la regla general ${ }^{147}$. Ello porque la legislación siempre regula conductas desde su vigencia, mientras que la adjudicación de efectos jurídicos siempre se refiere a hechos anteriores al pronunciamiento. Pues bien, la función característica de la CGR no es dar normas generales y abstractas (al modo del legislador) sino resolver situaciones particulares creando una jurisprudencia obligatoria en un contexto normativo estable.

\footnotetext{
44 Artículo 41, LEY No 19.880 de 2003.

45 Huepe (2018) pp. 103-110.

46 Elaborada con inspiración en Ávila (2016) pp. 70-71.

47 Cross y Harris (2004) p. 232.
} 
De lo anterior deriva un dato que es fundamental: el criterio contenido en la nueva jurisprudencia debe haber sido igualmente admisible en el contexto normativo que abrigaba a la antigua. Entonces, ¿de dónde viene la necesidad de una regla de irretroactividad del cambio de precedente? Deriva del artículo $6^{\circ}$ y 19 de la Ley 10.336 que le reconocen su valor normativo a la jurisprudencia administrativa. Estas normas impiden introducir un cambio de jurisprudencia haciendo la ficción de que los precedentes anteriores nunca formaron, a su vez, una jurisprudencia también obligatoria.

Las normas citadas también impiden que una nueva jurisprudencia altere en el presente los efectos de actos administrativos válidamente emitidos durante la vigencia del precedente anterior. Esto porque, de lo contrario, la eficacia de estas normas que consagran el valor normativo de la jurisprudencia de la CGR estaría siempre abierta a ser cuestionada en el presente; lo que pondría en duda valor los mencionados artículos como norma jurídica y, en consecuencia, del principio de legalidad. Por lo tanto, más allá de la idoneidad de un nuevo criterio que justifica el cambio, la implementación de un cambio jurisprudencial con efecto retroactivo total o parcial requiere una fundamentación más allá de la sola idoneidad.

Tercero, aunque un cambio de jurisprudencia sea idóneo, ello tampoco justifica en forma necesaria darle efecto inmediato o in actum al nuevo criterio. Un cambio brusco de jurisprudencia podría tener un efecto adverso sobre quienes han planificado su conducta sobre la base del precedente abandonado. Por esto, al modificar su jurisprudencia, la CGR puede tener el deber de considerar tal situación para efectos de ofrecer alguna medida de protección a los afectados. Por ejemplo, la entrada en vigor de un nuevo criterio podría ser diferida en el tiempo, pues si la CGR goza de discrecionalidad para determinar en qué momento cambiar de criterio, nada le impide señalar un plazo de vacancia para la entrada el vigor de la nueva jurisprudencia ${ }^{48}$.

Por esto, como forma de asegurar la previsibilidad de un cambio de criterio, la autoridad debe considerar que la mayor idoneidad no necesariamente justifica darle efecto inmediato al nuevo criterio: al respecto debe tener en cuenta la posibilidad de diferir la implementación del nuevo precedente para proteger a quienes han planificado su conducta conforme con el criterio que se propone abandonar, tal como se ha sugerido respecto de la invalidación de actos administrativos y de cambios de criterio de autoridades administrativas en general $^{49}$.

\section{1. ¿Cómo aplicar estos criterios?}

Para responder a la primera crítica formulada en el apartado anterior, podemos decir que la fundamentación de un cambio de criterio debe ser distinta a la de cómo se concretarán sus efectos en el tiempo. Para mostrar cómo debe operar esto en la práctica se volverá sobre dos casos ya analizados. Se comenzará con el caso que denominé Incompatibilidad de Remuneraciones. El dictamen 50.185 de 2007, que resolvió la incompatibilidad de las remuneraciones de los cargos de alta dirección pública con la de los concejales municipales.

48 Soto (1996) p. 54; Arancibia (2016) p. 180.

49 Letelier (2014) pp. 627-631; Bermúdez (2016) pp. 232-233. 
Phillips Letelier, Jaime " "El cambio de jurisprudencia por la Contraloría General de la República ..."

En particular, se trató del caso de una funcionaria que era al mismo tiempo directora de un servicio de salud e integrante de un concejo municipal.

El cambio consistió en que, antes del dictamen citado, se consideraba que, dentro de las excepciones a la obligación de dedicación exclusiva de los cargos de alta dirección pública, estaban los concejales municipales, pues ellos eran integrantes de "consejos de empresas o entidades del Estado" ${ }^{50}$. Pero luego se consideró que la Real Academia de la Lengua considera que el cargo de concejal (con "c" en la segunda sílaba) es una denominación específica para quien integra el concejo del municipio o ayuntamiento $\mathrm{y}$, en consecuencia, los concejales no estaban dentro de la excepción del artículo $1^{\text {o }}$ de la Ley 19.863 .

Podríamos preguntarnos si la anterior interpretación fue legal o ilegal, respecto de lo cual la CGR no se pronunció. En este caso, no estamos frente a un precedente ilegal. La palabra "consejo" en su segunda acepción, significa "[ó] rgano colegiado con la función de asesorar, de administrar o de dirigir una entidad"51. Así, resulta que el concejo del ayuntamiento o municipalidad es una especie de consejo en el sentido de que es un órgano colegiado con funciones de asesoría, administración o de dirección de una municipalidad. De este modo, no resulta inconcuso, al menos lingüísticamente, que el artículo $1^{\circ}$ de la Ley 19.863 no incluya también a miembros de concejos municipales, aunque la denominación específica de estos últimos se escriba distinto.

Con esto, es posible criticar la decisión de la CGR de darle efecto retroactivo parcial a la nueva jurisprudencia. En este caso, el cambio de criterio terminó por afectar a una persona que había adquirido la calidad de concejal y nombrada en un cargo público durante la vigencia de la jurisprudencia que incluía a los concejales en el artículo $1^{\circ}$ de la Ley 19.863. En este caso, la CGR solo debió dar efecto prospectivo a la nueva jurisprudencia, sin alcanzar con ello los efectos de elecciones o nombramientos anteriores a su vigencia.

Lo anterior podría ser criticado, pues en general se entiende que las normas del derecho público rigen in actum $^{52}$. Sin embargo, es preciso señalar que los actos válidamente perfeccionados durante la vigencia de un precedente conforme con la legalidad generan derechos adquiridos ${ }^{53}$. Por lo anterior, un cambio de jurisprudencia no puede ser aplicado para "revocar" actos que produjeron derechos adquiridos en forma válida ${ }^{54}$, salvo que la jurisprudencia abandonada sea declarada antijurídica.

En el caso que se viene comentando la CGR consideró que era más adecuada una interpretación restrictiva del artículo $1^{\circ}$ de la Ley 19.863, lo que no implica una declaración de ilegalidad del criterio anterior. Esto se justifica en lo que llamé "idoneidad de necesidad". Respecto de esto, podría decirse que, al evaluar la necesidad de un cambio de jurisprudencia (por razones de mérito, oportunidad o conveniencia) la CGR estaría evaluando

\footnotetext{
50 Artículo $1^{\circ}$ inciso 5, LEY 19.863 de 2003.

51 Real Academia Española de la Lengua (2021) Definición de consejo.

52 Alessandri, Somarriva y Vodanovic (2005) p. 258; Aylwin y Azócar (1996) p. 50; Silva (1993) p. 111. La CGR también lo ha entendido así. Respecto de reglamentos en materia ambiental, ver DICTÁMENES CGR No 75.903 (2014) y 58.037 (2016).

53 Dictamen CGR No 7041 (2013), Dictamen CGR 77.490 (2011), Dictamen CGR 4614 (2004), entre otros.

54 GuZMán (2019) pp. 123-125.
} 
"aspectos de mérito o de conveniencia de las decisiones políticas o administrativas", lo que está prohibido por su ley orgánica ${ }^{55}$.

Para salvar este problema es necesario determinar el alcance del artículo $21 \mathrm{~B}$ de la Ley 10.336 en esta materia. Esta norma le impide a la CGR evaluar aspectos de mérito o de conveniencia de las decisiones de las autoridades sometidas a su fiscalización. Pero la norma en comento no prohíbe que la CGR tome en cuenta cuestiones de mérito o de conveniencia al ejercer sus propias potestades. Por ejemplo, nada impide que la CGR evalúe la conveniencia de fiscalizar o no a determinado organismo, o de hacer una auditoria de tal o cual programa. Siguiendo este razonamiento, nada impide que la CGR evalúe la oportunidad, mérito o conveniencia de abandonar su propio precedente, dentro del marco legal.

El artículo $21 \mathrm{~B}$ está dirigido a que la CGR no invada los márgenes de discrecionalidad y apreciación de otras autoridades, pero no le impide evaluar aspectos de mérito de sus propias decisiones. Por lo demás, la interpretación contraria le haría impracticable el cumplimiento de sus funciones a la CGR. De este modo, hay que entender que la CGR sí está habilitada para resolver sobre la necesidad de abandonar o no un precedente.

Sin embargo, que un nuevo criterio tenga idoneidad de necesidad no significa que por ello estará justificado darle efecto retroactivo o inmediato. A pesar de que se trata de elementos que están conectados, una cosa es por qué debiésemos cambiar de criterio y otra es cómo debiesen desplegarse sus efectos en el tiempo.

Un caso donde se podría haber mitigado el efecto inmediato de un cambio jurisprudencial es el que denominé Máquinas de Juego. Como se recordará, en este caso, una asociación gremial impugnó por medio de una acción de amparo económico lo resuelto por la CGR en el dictamen 92.308 de 2016, en lo relativo al procedimiento para autorizar máquinas de juego. En este pronunciamiento, la CGR modificó su jurisprudencia relativa al procedimiento para obtener una patente municipal para operar máquinas de juegos. La jurisprudencia vigente hasta ese momento señalaba que para obtener la patente el solicitante solo debía acreditar ante el municipio respectivo, con cualquier medio de prueba, que la máquina correspondía a un juego donde predominaba la habilidad o destreza, y no la suerte. Lo anterior se debe a que aquellos juegos donde predomina la suerte están, por regla general, prohibidos por ley ${ }^{56}$.

Pero en virtud del citado dictamen se determinó que, para otorgar la patente, la municipalidad debía tener en cuenta el catálogo de juegos de azar de la Superintendencia de Casinos y, en caso de dudas, pedir un informe a la autoridad mencionada. Además, declaró que la nueva jurisprudencia no afectaba a las patentes ya otorgadas ${ }^{57}$. Con esto, el cambio de jurisprudencia no afectó la validez de actos administrativos pasados y así la CGR solo dio efecto prospectivo a su decisión. Además, conociendo de un recurso de protección interpuesto en contra de este dictamen, la Corte Suprema resolvió que el pronunciamiento de la CGR respondía a una "necesidad pública actual y manifiesta" ante la dispersión de

\footnotetext{
55 Artículo 21 B, LeY No 10.336 de 1952.

56 Artículos 1466 y 2259, Código Civil, Chile; Ley No 19.995 de 2005.

57 Dictamen CGR No 92.308 (2016).
} 
Phillips Letelier, Jaime "El cambio de jurisprudencia por la Contraloría General de la República ..."

criterios para determinar si las máquinas son de azar o no, lo que justifica en forma suficiente el cambio de criterio ${ }^{58}$.

En este caso, también se puede afirmar que el cambio de precedente no implica una declaración de ilegalidad del anterior. El criterio anterior podía considerarse como más permisivo, pues cada municipalidad debía valorar si la máquina de juego era de aquellas donde predominaba la destreza o el azar ${ }^{59}$. Pero ello no implica que fuese ilegal. Y lo anterior no es óbice para que la CGR introduzca una nueva jurisprudencia que obligue a las municipalidades a coordinarse de mejor manera con la autoridad sectorial especializada, señalándole la necesidad de ejercer sus poderes para solicitar informes ${ }^{60}$, y de abstenerse a autorizar las máquinas que la autoridad especializada considere como sujetas a la prohibición legal.

Sin embargo, esta decisión de la CGR podría ser cuestionada en relación con su efecto inmediato ${ }^{61}$. Para entender esto es necesario tener en cuenta que el precedente de la CGR sirve como norma para la toma de decisiones de las autoridades administrativas y, por tanto, es seguido también por los particulares porque el precedente de la CGR determina el alcance que tienen las potestades de los distintos órganos sobre ellos. Un cambio jurisprudencial con efecto inmediato puede afectar a quién adquirió determinadas máquinas (y, por tanto, hizo algún gasto o inversión) y esperaba una autorización favorable; criterio que se extendería a la resolución de solicitudes pendientes formuladas ante la autoridad bajo la jurisprudencia abandonada.

Se podría pensar que estas son meras expectativas que no merecen protección. Sin embargo, ello puede ser cuestionado. En situaciones de inestabilidad normativa, la autoridad tiene el deber de anunciar o anticipar su cambio de criterio para no lesionar los intereses de quien ha obrado conforme con una norma que se pretende derogar ${ }^{62}$. Incluso, en relación con la declaración de nulidad de un acto administrativo, se ha aceptado la posibilidad de diferir los efectos de tal declaración como forma de proteger expectativas generadas por el acto nulo ${ }^{63}$.

La protección de expectativas de estabilidad o de obtener una determinada decisión sobre la base del precedente de CGR está justificada por la influencia que este tiene en la planificación de conducta de los individuos. Si los particulares ejercen su libertad teniendo en cuenta el precedente administrativo (por ejemplo, haciendo disposiciones patrimoniales o inversiones) y luego son en forma especial afectados por el cambio, podría configurarse una infracción a las garantías de libertad económica e igualdad ante la ley ${ }^{64}$.

Con todo, para proteger estas expectativas es necesario proceder con cautela. No deben ser protegidas como si estuviesen siendo afectadas por decisiones con un efecto re-

\footnotetext{
58 FIDEN A.G. con CONTRALOR GENERAL DE LA REPÚblica (2018) considerando $13^{\circ}$.

59 Dictámenes CGR No 1857 (2014) y dictamen CGR 46.631 (2011).

60 Artículo 37, LEY No 19.880 de 2003.

${ }^{61}$ En el mismo sentido, se podrían cuestionar los Dictámenes CGR No 39.766 (2020), DiCTAMEN CGR 4692.337 (2016) y DiCTAMEN CGR 39.341 (2016), en relación con el cambio de jurisprudencia introducido por el DiCTAMEN CGR No 4000 (2016).

62 Bermúdez (2016) pp. 232-233.

63 LeTElier (2014) pp. 629-630.

64 Phillips (2020a) pp. 205-215.
} 
troactivo prohibido o como si se tratase de derechos adquiridos. Si lo que se ha afectado es la libertad individual y la igualdad ante la ley, solo es necesario permitir al particular redirigir su conducta antes de ser afectado por el nuevo criterio. Por esto, pienso que nada impide que la CGR difiera la entrada en vigor de la nueva jurisprudencia, para no afectar a quien se ha planificado o realizado actos conforme con el criterio abandonado. Esto ha sido considerado como una solución en otros sistemas donde la jurisprudencia es fuente formal directa del derecho ${ }^{65}$.

\section{LÍMITES PARA LA RETROACTIVIDAD FAVORABLE}

Las normas que consagran la obligatoriedad de la jurisprudencia administrativa de la CGR impiden dar efecto retroactivo a un cambio de criterio. Pero, en caso de que el cambio de criterio sea favorable a los interesados en el procedimiento administrativo, se podría aplicar el artículo 52 de la Ley 19.880.

Por ejemplo, en el caso Patente de Invención la CGR entendió en el dictamen 16.587 de 2019 que los derechos derivados del otorgamiento de una patente de invención sí eran una "exigencia de tramitación". Por tanto, en caso de incumplirse el plazo previsto en el artículo 18 bis E de la Ley 19.039, la solicitud podía ser desarchivada sin perder el derecho a la preferencia establecido en el artículo 45 del mismo cuerpo legal. Con todo, el dictamen 25.534 de 2019 entendió que tal criterio regía para el futuro y solo beneficiaba a quienes provocaron el cambio de criterio y no a quienes cuyo expediente ya se hubiese archivado antes de su vigencia.

En este caso, aquellos particulares cuyo expediente fue archivado poco antes del cambio de criterio no se vieron beneficiados. Con todo, tratándose de un nuevo criterio favorable al interesado, en la medida que nadie hubiese adquirido un derecho de preferencia en el tiempo intermedio, nada impedía dar efecto retroactivo a la nueva jurisprudencia. Esta solución, si bien a primera vista razonable, presenta la pregunta sobre cuáles debiesen ser los límites de esta retroactividad favorable. Una aplicación extensiva de la excepción del artículo 52 de la Ley 19.880 podría implicar dar lugar a una revisión indefinida de expedientes archivados en el pasado, lo que generaría una excesiva inseguridad jurídica. De este modo, aunque beneficiar solo a quien provoca el cambio de criterio suponga una discriminación arbitraria, ello parece ser la única solución aceptable.

No obstante, ello no tiene por qué ser así. Todo depende de bajo qué parámetros la autoridad dé lugar a la aplicación retroactiva de la nueva jurisprudencia. La autoridad no debe estar obligada a aplicar la excepción de retroactividad del artículo 52 de la Ley 19.880 cada vez que ello sea posible, porque de lo contrario se podría dar lugar a una retroactividad favorable sin límites. Para evitar esto, la posibilidad de dar efecto retroactivo favorable a un acto administrativo ha de ser mirada como una potestad discrecional que debe ser usada cautamente.

En el caso que se viene comentando, el contexto normativo permitía dar lugar a la retroactividad favorable con una razonable limitación. El artículo 45 de la Ley 19.039 establece un plazo de 120 días para desarchivar solicitudes que hayan incumplido exigencias

65 Cross y Harris (2004) pp. 229-230. 
Phillips Letelier, Jaime "El cambio de jurisprudencia por la Contraloría General de la República ..."

de tramitación. En este contexto, nada impide aplicar retroactivamente el nuevo criterio, pero respetando el plazo de 120 días que establece la regulación. Por esto, considero que en la causa Farmacología en Aquacultura FAV S.A. con INAPI el recurso interpuesto debió ser acogido, pues la recurrente sí pagó los derechos dentro del plazo de 120 días. De esta manera, se evita introducir un criterio diferenciador azaroso como es aquel del momento en que se hizo una solicitud ante la CGR, se beneficia a aquellos particulares cuyas solicitudes fueron archivadas poco antes del cambio de jurisprudencia y se pone un límite razonable a la aplicación retroactiva de la nueva jurisprudencia.

En este sentido, para responder a la segunda crítica formulada en el apartado anterior, la solución correcta estaría en aplicar los mismos plazos establecidos en la regulación especial o general para que decisiones pasadas puedan ser revisadas conforme con la nueva jurisprudencia aplicando la retroactividad favorable. A falta de una regla expresa, nada impide que la CGR dé lugar a un cambio de criterio solo con efecto retroactivo parcial o prospectivo para casos cuyos hechos se verifiquen en el futuro.

Por ejemplo, en el caso Pensiones de Desahucio se ha utilizado el criterio que discrimina según el momento en que se produjo la jubilación, beneficiando a quienes provocaron el cambio ${ }^{66}$. En tal situación, se podría beneficiar a todos los pensionados con el nuevo criterio, modificando sus pensiones con efecto retroactivo parcial o inmediato, pero sin darles efecto retroactivo total, tal como lo ha sugerido una disidencia en la Corte Supre$\mathrm{ma}^{67}$. Esto permitiría ajustar las pensiones hacia el futuro, pero sin otorgar pagos retroactivos durante la vigencia del precedente anterior.

\section{CAMBio DE JURISPRUDENCIA POR RAZONES DE LEGALIDAD}

En principio, los actos administrativos dictados sobre la base de una jurisprudencia contraria a derecho debiesen poder ser retirados con efecto retroactivo, pues la declaración de nulidad tiene por naturaleza ese efecto ${ }^{68}$. Lo anterior puede tener consecuencias difíciles de prever. Por esto, es comprensible que la CGR prefiera guardar silencio sobre este problema y limitarse a declarar que su cambio de jurisprudencia no tiene efecto retroactivo, aunque el cambio se sustente en la idoneidad legal del nuevo precedente. Sin embargo, este silencio es problemático porque le ha significado a la CGR ver impugnadas y revertidas sus decisiones en algunos casos. Por lo anterior, para responder a la tercera crítica formulada en el apartado anterior, es necesario que la CGR aborde de modo explícito el problema de la ilegalidad de la jurisprudencia abandonada cuando ello sea pertinente.

Para que exista un precedente contrario a derecho debe existir una infracción legal, lo que se manifiesta de tres maneras ${ }^{69}$ : primero, por una contravención formal, cuando no se ejecuta lo que la ley manda, cuando se ejecuta lo prohibido o se impide realizar lo permitido; segundo, por falsa aplicación, cuando se manda, prohíbe o permite algo en un

\footnotetext{
${ }_{66}$ Ver Dictámenes CGR No 18.219 (2016), Dictamen CGR 40.086 (2015) y Dictamen CGR 14.292 (2007).

67 Neftalí Aguayo con Carabineros de Chile (2013) considerando $5^{\circ}$ del voto de minoría.

68 Valdivia (2018) pp. 406-407.

69 Mosquera y Maturana (2017) pp. 354-355. Ver también, artículo 767, Código de Procedimiento Civil, Chile.
} 
supuesto no previsto por la ley; tercero, por errónea interpretación, cuando se entiende de modo erróneo los términos de lo que manda el ordenamiento jurídico.

Ahora bien, es importante determinar cuándo existe tal contravención formal. Ella no existe cuando una jurisprudencia termina por ser abandonada producto de un cambio de valoración sobre cómo debiese responder el ordenamiento jurídico en un contexto social determinado. Dicho de otro modo, no se trata de situaciones de ilegalidad de la jurisprudencia abandonada, sino que la distinta comprensión que se llega a tener de un fenómeno jurídico es lo que sustenta el cambio de criterio, lo que no equivale a declarar la ilegalidad de un precedente. Así, no estaríamos frente a una situación donde se justifique aplicar el efecto retroactivo de la nulidad.

Como ejemplo de lo anterior, se puede considerar el caso Contratas Administrativas y el caso Prescripción de Sanciones, ya analizados más arriba. En estos casos no existe una declaración de ilegalidad de un precedente, sino un cambio en la comprensión de un determinado fenómeno jurídico. En este contexto, por razones de seguridad jurídica la CGR debe fijar el momento en que deja de regir la antigua jurisprudencia y comienza la nueva. Esto con una regla, como se ha dicho, que evite tanto la discriminación arbitraria como la lesión de la certeza jurídica dando lugar en forma indiscriminada a la retroactividad.

Más allá de estos casos, la regla general debiese ser la de retirar con efecto retroactivo las decisiones tomadas sobre la base del precedente ilegal. Por ejemplo, en el caso Tarifas por Inspecciones, la CGR ordenó modificar un reglamento que permitía al SAG cobrar por inspecciones que estaba obligado a realizar de oficio. El cambio solo debía regir hacia el futuro y la Corte Suprema validó tal planteamiento rechazando una acción por pago de lo no debido ${ }^{70}$. No obstante, en un caso como este se debió entender que la antigua jurisprudencia era ilegal y que la nueva debió ser aplicada con efecto retroactivo, pues de la orden se podía concluir que los cobros eran ilegales. Así, la acción de cobro de pesos debió ser acogida en la medida que lo permitiesen los plazos de prescripción ${ }^{71}$.

También se pueden criticar los argumentos de la Corte Suprema en Mamani con Municipalidad de Putre y Contraloría Regional de Arica y Parinacota. La municipalidad demandada hizo un pago retroactivo con ocasión de un cambio de criterio que insinuaba la ilegalidad de la anterior jurisprudencia. Este pago fue estimado como contrario a derecho por la Contraloría Regional de ese lugar por haberse hecho respecto de periodos en que rigió el precedente anterior. Por esto, se terminó por emitir una orden de reintegro en contra del beneficiado por el pago retroactivo. La Corte Suprema dejó sin efecto tal orden de reintegro. Esto porque consideró que la aplicación del antiguo precedente era contraria a la igualdad ante la ley y la buena fe administrativa, pues existía un derecho adquirido a conservar los pagos recibidos ${ }^{72}$.

Al cambiar de criterio, la CGR habla de que el antiguo criterio restringía la aplicación de una nueva ley a la que el legislador quería dar un efecto general ${ }^{73}$. Con esto, se

\footnotetext{
70 Dictamen CGR No 18.390 (2007); AbUfrut Limitada con SERVICIO Agrícola y Ganadero (2015).

71 Pierry (2017) pp. 238-242.

72 Mamani con Municipalidad de Putre y otro (2019) considerandos $5^{\circ}$ y $6^{\circ}$.

73 Dictámen CGR No 81.956 (2014), en relación con el DiCTAMen CGR No 41.047 (2014).
} 
puede ver que exista una contravención formal a la ley, aunque la CGR no menciona cómo ello debiese afectar en la determinación de los efectos en el tiempo del nuevo criterio. En este contexto, no había ninguna necesidad de acudir a la igualdad ante la ley y la buena fe administrativa para validar el pago retroactivo hecho por la municipalidad. Más bien se debió entender que la municipalidad obró conforme a derecho al otorgar un pago retroactivo aún respecto de periodos anteriores a la vigencia del dictamen 81.956 de 2014, pues tal pronunciamiento obligaba a considerar que el anterior precedente contenía una contravención formal a la Ley 20.742 .

En estos casos, la CGR puede perfectamente declarar la ilegalidad de su propio precedente y dar las órdenes que en derecho correspondan. Por ejemplo, invalidar actos administrativos, recuperar dineros entregados ilegalmente o proceder a hacer restituciones, siempre dentro de los plazos de caducidad o de prescripción que corresponda aplicar en cada caso. Más allá de esto, también podría la CGR mitigar los efectos retroactivos de su cambio de jurisprudencia aplicando su propia doctrina sobre protección de la confianza y "situaciones jurídicas consolidadas", tal como se lo ha sugerido una disidencia de la Corte Suprema ${ }^{74}$. En ese caso, habrá que analizar caso a caso cuándo la confianza depositada en la jurisprudencia de la CGR ha generado expectativas merecedoras de protección ${ }^{75}$.

\section{CONCLUSIONES}

El análisis hecho hasta ahora muestra que el problema de los efectos en el tiempo de un cambio de jurisprudencia merece una cuidadosa atención. La necesidad de fundamentar la decisión en cuanto a su temporalidad y los efectos temporales de la declaración de ilegalidad de un precedente han recibido poca atención. Así, del análisis hecho, se pueden sacar las siguientes conclusiones:

1. Al modificar su jurisprudencia, la CGR no solo debe justificar la necesidad de cambiar de criterio, sino que además debe incorporar una argumentación que le dé sustento a la determinada forma en que concretó los efectos en el tiempo del nuevo criterio. Para lo anterior es útil la consideración separada de los siguientes elementos: (1) la idoneidad del nuevo criterio, (2) la justificación del efecto retroactivo y (3) la justificación del efecto inmediato.

2. Por regla general, la CGR no puede modificar su precedente con efecto retroactivo total o parcial. La idoneidad de necesidad del nuevo criterio no justifica darle efecto retroactivo a cambios de precedente desfavorables. En caso de que el nuevo precedente sea favorable a los interesados, puede darle efecto retroactivo total o parcial, pero eso no significa que deba hacerlo siempre. La autoridad debe evaluar discrecionalmente la necesidad de aplicar la regla de retroactividad favorable. En ese ejercicio, se debe adoptar una regla que evite tanto la introducción de discriminacio-

\footnotetext{
74 ÓsCAR ULLOA Y OTROS CON GENDARMERÍ DE CHILE (2012), considerando 4 o del voto de minoría.

75 Phillips (2020a) pp. 217-219.
} 
nes arbitrarias como de una excesiva retroactividad favorable que afecte en demasía la seguridad jurídica.

3. La CGR debe modificar con efecto retroactivo su jurisprudencia cuando la jurisprudencia abandonada contenía una contravención formal a derecho. Ello no ocurre cuando la jurisprudencia abandonada era de aquellas que el ordenamiento admitía como posibles o cuando el cambio de criterio obedece al desarrollo de la nueva valoración sobre cómo debiese responder el ordenamiento jurídico a un determinado caso. Más allá de estas situaciones, la legalidad deberá ser restaurada con efecto retroactivo desde la producción del vicio o ab initio, procediendo las acciones restitutorias o indemnizatorias correspondientes. Con todo, en esta situación, la CGR y los tribunales de justicia debiesen tener en cuenta la eventual existencia de expectativas protegibles generadas por la jurisprudencia abandonada.

\section{BIBLIOGRAFÍA}

Alessandri Rodríguez, Arturo, Somarriva Undurraga, Manuel y Vodanovic Haklicka, Antonio (2005): Tratado de derecho civil: partes preliminar y general (Santiago, Editorial Jurídica de Chile, séptima edición).

Ávila, Humberto (2016): Certainty in Law (Switzerland, Springer).

Arancibia Mattar, Jaime (2016): "Los puntos de prueba en litigios de impugnación de actos administrativos", en Arancibia Mattar, Jaime y Romero Seguel, Alejandro (edits.) La prueba en la litigación pública (Santiago, Librotecnia) pp. 161-190.

Aylwin Azócar, Patricio, y Azócar Brunner, Eduardo (1996): Manual de derecho administrativo (Santiago, Universidad Nacional Andrés Bello).

Barrero Rodríguez, María Concepción (2003): "El respeto de los derechos adquiridos", Documentación Administrativa, No 263: pp. 137-183.

Bermúdez Soto, Jorge (2016): "El principio de protección de la confianza legítima como fundamento y límites a la actuación de la Administración del Estado”, en FERradA Bórquez, Juan Carlos, Bermúdez Soto, Jorge y Urrutia Silva, Osvaldo (edits.) Doctrina y enseñanza del Derecho Administrativo chileno: estudios en homenaje a Pedro Pierry Arrau (Valparaíso, Ediciones Universitarias de Valparaíso) pp. 223-239.

Boettiger Philipps, Camila (2009): "El principio de buena fe en la jurisprudencia de la Contraloría General de la República en materia urbanística”, Revista de Actualidad Jurídica, vol. 19, No 1: pp. 309-326.

Claro Solar, Luis (2013): Explicaciones de derecho civil chileno y comparado, Tomo I (Santiago, Editorial Jurídica de Chile).

Cross, Rupert y Harris, J.W. (2004): Precedent in English Law (Oxford, Clarendon Press, cuarta edición).

Cordero Quinzacara, Eduardo (2020a): "El plazo en la prescripción de las infracciones y sanciones administrativas ante el principio de proporcionalidad", Revista Chilena de Derecho, vol. 47, No 2: 359-384. 
Phillips Letelier, Jaime — "El cambio de jurisprudencia por la Contraloría General de la República ..."

Cordero Vega, Luis (2020b): "El control de la Corte Suprema sobre los precedentes de la Contraloría General de la República”, Revista Chilena de la Administración del Estado, No 4, segundo semestre: pp. 125-135.

Díez SaSTRE, Silvia (2008): El precedente administrativo. Fundamentos y eficacia vinculante (Madrid, Marcial Pons).

Fuentes Mondaca, Óscar (2020): "La invalidación de los permisos de edificación. Criterios de la jurisprudencia”, Revista Chilena de la Administración del Estado, No 4, segundo semestre: pp. 21-42.

GuZMÁn Brito, Alejandro (2019): La interpretación administrativa en el derecho chileno (Santiago, Legal Publishing Chile, segunda edición corregida y revisada).

Hart, H.L.A. (2012): The Concept of Law (Oxford, Oxford University Press, tercera edición). Huepe Artigas, Fabián (2018): Discrecionalidad administrativa y razonabilidad (Santiago, Legal Publishing Chile).

Letelier Wartenberg, Raúl (2014): “Contra la confianza legítima como límite a la invalidación de actos administrativos”, Revista Chilena de Derecho, vol. 41, No 2: pp. 609-634.

Madariaga Gutiérrez, Mónica (1993): Seguridad jurídica y administración pública en el siglo XXI (Santiago, Editorial Jurídica de Chile, segunda edición).

Millar Silva, Javier (2012): "El principio de protección de la confianza legítima en la jurisprudencia de la Contraloría General de la República: una revisión a la luz del Estado de Derecho" en Contraloría General de la República, La Contraloría General de la República: 85 años de vida institucional (1927-2012) (Santiago, Contraloría General de la República) pp. 417-430.

Mosquera Ruiz, Mario y Maturana Miquel, Cristina (2017): Los recursos procesales (Santiago, Editorial Jurídica de Chile, tercera edición actualizada).

Phillips Letelier, Jaime (2020a): La protección de expectativas en el derecho administrativo. Una propuesta para la aplicación del principio de protección de la confianza (Valencia, Tirant lo Blanch).

Phillips Letelier, Jaime (2020b): "La fuerza obligatoria del precedente de la Contraloría General de la República. Una regla chilena de stare decisis", Revista de Derecho Administrativo Económico, No 31, enero-junio 2020: pp. 149-176.

Pierry Arrau, Pedro (2017): Derecho administrativo. Obra reunida (Valparaíso, Ediciones Universitarias de Valparaíso).

Ponce Correa, Patricio (2020): “Delegación de la facultad de destitución. Su revisión a partir de la jurisprudencia de la Contraloría General de la República”, Revista Chilena de la Administración del Estado, No 4, segundo semestre: pp. 43-70.

Real Academia Española de la Lengua (2020): Definición de consejo. Disponible en: https://dle.rae.es/consejo. Fecha de consulta: 16 de diciembre de 2020.

Román Cordero, Cristián (2018): "Dictámenes de la Contraloría General de la República y acción declarativa de mera certeza (comentario a la sentencia del Tribunal Constitucional rol No 3.283)", en Fermandois Vöhringer, Arturo y López Díaz, Francisco (edits.), Sentencias destacadas 2017. Una mirada desde las políticas públicas (Santiago, Ediciones Libertad y Desarrollo) pp. 389-433. 
Schneider, Jens-Peter (2011): "Seguridad jurídica y protección de la confianza en el derecho constitucional y administrativo alemán”, Documentación Administrativa, No 263: pp. 249-279.

Silva Cimma, Enrique (1993): Derecho administrativo chileno y comparado, Tomo I (Santiago, Editorial Jurídica de Chile).

Sото Kloss, Eduardo (1999): "Acerca de la obligatoriedad de los precedentes en la actividad administrativa del Estado", Revista Chilena de Derecho, vol. XXVI, No 2: pp. 399-403.

Soтo Kloss, Eduardo (1996): Derecho administrativo. Bases fundamentales, Tomo II (Santiago, Editorial Jurídica de Chile).

Valdivia Olivares, José Miguel (2018): Manual de derecho administrativo (Valencia, Tirant lo Blanch).

\section{JURISPRUDENCIA}

I. JURISPRUDENCIA JUDICIAL

Farmacología en Aquacultura Veterinaria FAV S.A. con INAPI (2020): Corte Suprema, 28 de septiembre de 2020, rol 117-167-2020 (recurso de protección).

Farmacología en Aquacultura VETERINARIa FAV S.A. con INAPI (2020): Corte de Apelaciones de Santiago, 10 de agosto de 2020, rol 1990-2020 (recurso de protección).

Sepúlveda y CÁRCAmo con Contraloría Regional de los Ríos (2020): Corte Suprema, 10 de junio de 2020, rol 41.254-2019 (recurso de protección).

Mamani con Municipalidad de Putre y otro (2019): Corte Suprema, 14 de agosto de 2019, rol 14.178-2019 (recurso de protección).

FIDEN A.G. con Contralor GENERAL de LA REPÚblica (2018): Corte Suprema, 30 de octubre de 2018, rol 19.054-2018 (amparo económico).

Laboratorios lafi ltda. con Instituto de Salud Pública (2018): Corte Suprema, 23 de octubre de 2018, rol 44.510-2017 (reclamación artículo 171, Código Sanitario).

Abufrut Limitada con SAG y Fisco de Chile (2015): Corte Suprema, 28 de mayo de 2015, rol 21.920-2014 (pago de lo no debido).

CMPC MAdERAS S.A. CON SAG (2013): Corte Suprema, 30 de enero de 2013, rol 17-2013 (cobro de pesos).

Neftalí Aguayo con Carabineros de Chile (2013): Corte Suprema, 25 de julio de 2013, rol 2720-2013 (recurso de protección).

Óscar Ulloa y otros con Gendarmería de Chile (2012): Corte Suprema, 28 de noviembre de 2012, rol 5508-2012 (recurso de protección).

CMPC Maderas S.A. con SerVicio Agrícola y Ganadero (2013): Corte de Apelaciones de Santiago, 19 de noviembre de 2012, rol 196-2011 (cobro de pesos).

BANCO CRÉDITO E INVERSIONES (1966): Corte Suprema, 12 de julio de 1966 (inaplicabilidad) Revista de Derecho y Jurisprudencia tomo 63 (1966), sección 3º, pp. 93-95.

ARturo AlESSANDRI (1965): Corte Suprema, 27 de diciembre de 1965 (inaplicabilidad) Revista de Derecho y Jurisprudencia tomo 62 (1965), sección 3º, pp. 114-119. 
Phillips Letelier, Jaime “ "El cambio de jurisprudencia por la Contraloría General de la República ...”

II. JURISPRUDENCIA ADMINISTRATIVA

DictAMEN CGR No 74.506 de 2021.

DiCTAMEN CGR No 62.732 de 2020.

DiCTAMEN CGR No 39.766 de 2020.

Dictamen CGR No 25.714 de 2019.

Dictamen CGR No 26.211 de 2018.

Dictamen CGR No 24.731 de 2019.

Dictamen CGR No 25.534 de 2019.

Dictamen CGR Na 16.587 de 2019.

Dictamen CGR No 20.921 de 2018.

Dictamen CGR No 92.337 de 2016.

Dictamen CGR No 92.308 de 2016.

Dictamen CGR No 68.075 de 2016.

Dictamen CGR No 68.704 de 2016.

Dictamen CGR No 58.037 de 2016.

Dictamen CGR No 53.891 de 2016.

Dictamen CGR No 46.046 de 2016.

Dictamen CGR No 39.341 de 2016.

Dictamen CGR No 22.766 de 2016.

DiCTAMEn CGR No 18.219 de 2016.

Dictamen CGR No 4000 de 2016.

Dictamen CGR No 40.086 de 2015.

Dictamen CGR No 81.956 de 2014.

DiCTAMEN CGR No 75.903 de 2014.

Dictamen CGR No 41.047 de 2014.

Dictamen CGR No 1857 de 2014.

DiCTAMEN CGR No 7041 de 2013.

Dictamen CGR No 77.490 de 2011.

Dictamen CGR No 46.631 de 2011.

Dictamen CGR No 27.314 de 2010.

Dictamen CGR No 57.424 de 2009.

Dictamen CGR No 48.688 de 2009.

Dictamen CGR No 60.094 de 2008.

Dictamen CGR No 50.185 de 2007.

Dictamen CGR No 14.292 de 2007.

Dictamen CGR No 44.902 de 2006.

Dictamen CGR No 22.437 de 2006.

Dictamen CGR No 51.963 de 2005.

Dictamen CGR No 19.598 de 2004.

Dictamen CGR No 4614 de 2004.

Dictamen CGR No 37.859 de 2000. 


\section{NORMAS E INSTRUMENTOS CITADOS}

Chile, Constitución Política de la República (22/9/2005).

Chile, Código Civil.

Chile, Código de Procedimiento Civil.

Chile, Código Penal.

Chile, Ley No 20.742 (1/4/2014), perfecciona el rol fiscalizador del consejo, entre otras materias.

Chile, Ley No 19.995 (7/1/2005), establece las bases generales para la autorización, funcionamiento y fiscalización de casinos de juego.

Chile, Ley No Ley 19.882 (236/2003), regula nueva política de personal a los funcionarios públicos que indica.

Chile, Ley No 19.880 (29/05/2003), establece bases de los procedimientos administrativos que rigen los actos de los órganos de la Administración del Estado.

Chile, Ley No 19.863 (6/2/2003), sobre remuneraciones de cargos de gobierno y cargos críticos de la Administración Pública.

Chile, Ley No 19.039 (25/1/1991), establece normas aplicables a los privilegios industriales y protección de los derechos de propiedad industrial.

Chile, Ley No 18.575 (5/12/1986), Ley orgánica constitucional de bases generales de la Administración del Estado.

Chile, Ley No 14.171 (26/10/1970), Cambia nombre al Ministerio de Economía, entre otras materias.

Chile, Ley No 10.336 (12/5/1952), sobre organización y atribuciones de la Contraloría General de la República.

Chile, Ley s/n (7/10/1861), sobre efecto retroactivo de la ley. 
